\title{
The Level of Europium-154
}

\section{Contaminating Samarium-153-} EDTMP Activates the Radiation Alarm System at the US Homeland Security Checkpoints

\author{
Mohammed Najeeb Al Hallak ${ }^{\mathrm{a}}$ Matt McCurdy ${ }^{\mathrm{a}}$ \\ Nicolas Zouain ${ }^{a, b}$ Justin Hayes ${ }^{b}$ \\ aUniversity of North Dakota School of Medicine and Health Sciences, and \\ ${ }^{\mathrm{b}}$ MeritCare Roger Maris Cancer Center, Fargo, N. Dak., USA
}

\section{Key Words}

Samarium-153-EDTMP · Europium-154 · Bone metastases · Radiation alarm

\begin{abstract}
${ }^{153} \mathrm{Sm}$-EDTMP is a radiopharmaceutical composed of EDTMP (ethylenediaminetetramethylenephosphonate) and Samarium-153 [1]. ${ }^{153} \mathrm{Sm}$-EDTMP has an affinity for skeletal tissue and concentrates in areas with increased bone turnover; thus, it is successfully used in relieving pain related to diffuse bone metastases [1]. The manufacturing process of ${ }^{153} \mathrm{Sm}$-EDTMP leads to contamination with ${ }^{154} \mathrm{Eu}$ (Europium154) [2]. A previous study only alluded to the retention of ${ }^{154} \mathrm{Eu}$ in the bones after receiving treatment with ${ }^{153} \mathrm{Sm}$-EDTMP [2]. Activation of the alarm at security checkpoints after ${ }^{153} \mathrm{Sm}$-EDTMP therapy has not been previously reported. Two out of 15 patients who received ${ }^{153} \mathrm{Sm}$-EDTMP at Roger Maris Cancer Center (Fargo, N. Dak., USA) activated the radiation activity sensors while passing through checkpoints; one at a US airport and the other while crossing theAmerican-Canadian border. We assume that the ${ }^{154} \mathrm{Eu}$ which remained in the patients' bones activated the sensors.

Methods: In order to investigate this hypothesis, we obtained the consent from 3 of our 15 patients who received ${ }^{153} \mathrm{Sm}$-EDTMP within the previous 4 months to 2 years, including the patient who had activated the radiation alarm at the airport. The patients were scanned with a handheld detector and a gamma camera for energies from $511 \mathrm{keV}$ to $1.3 \mathrm{MeV}$.
\end{abstract}

Results: All three patients exhibited identical spectral images, and further analysis showed that the observed spectra are the result of ${ }^{154} \mathrm{Eu}$ emissions.

Conclusion: Depending on the detection thresholds and windows used by local and federal authorities, the remaining activity of ${ }^{154} \mathrm{Eu}$ retained in patients who received ${ }^{153} \mathrm{Sm}$-EDTMP could be sufficient enough to increase the count rates above background 


\begin{tabular}{|c|c|c|c|}
\hline $\begin{array}{l}\text { Cose Reports in } \\
\text { Bincialy }\end{array}$ & $\begin{array}{l}\text { Case Rep Oncol 2009;2:157-161 } \\
\text { D0I: } 10.1159 / 000235809\end{array}$ & Published online: August 28, 2009 & $\begin{array}{l}\text { @ } 2009 \text { S. Karger AG, Basel } \\
\text { ISSN 1662-6575 } \\
\text { www.karger.com/cro }\end{array}$ \\
\hline
\end{tabular}

levels and activate the sensors. At Roger Maris Cancer Center, patients are now informed of the potential consequences of ${ }^{153} \mathrm{Sm}$-EDTMP therapy prior to initiating treatment. In addition, patients treated with ${ }^{153} \mathrm{Sm}$-EDTMP at Roger Maris Cancer Center receive laminated cards stating the date and the dose of treatment, as well as a statement that the holder may activate the alarm at the security checkpoints.

\section{Intoduction}

Several modalities are applied for palliative therapies for metastatic bone pain, including the use of opioid analgesics and systemic chemotherapy. However, most of the patients with hormone-resistant prostate cancer are elderly and frail and do not tolerate the chemotherapy well. External beam radiotherapy provides excellent palliation for focal painful bone lesions; however, in patients with systemic disease, repeated courses may be required for palliation [3].

Another treatment option for the pain secondary to metastatic bone disease is the administration of bone-seeking radiopharmaceutical agents. These include phosphorus32, strontium-89 and samarium-153 [4]. Phosphorus-32 and strontium-89 have been studied extensively. Both of these agents are effective in relieving the pain from osteoblastic metastases, but both have properties that limit their utility. The long physical half-life of strontium-89 (50.5 days) results in a slow delivery of the dose of radiation as well as a prolonged and variable suppression of the hematopoietic elements [5]. However, the physical half-life of ${ }^{153} \mathrm{Sm}$ is $46.3 \mathrm{~h}$ [6], and its excretion is completed $6 \mathrm{~h}$ after administration [7]. The ${ }^{153} \mathrm{Sm}$-EDTMP complex localizes to bone with greater avidity for areas of bone turnover [8-10]. The areas of metastatic involvement can accumulate significant amounts of ${ }^{153} \mathrm{Sm}$-EDTMP compared to surrounding normal bone $[7,11]$. This form of treatment targets multiple osteoblastic sites simultaneously, both symptomatic and asymptomatic. In the latter case, it may delay the onset of the symptoms of such sites for several months and, therefore, delay the need for treatment [11]. Usually, patients can benefit from a single injection, with pain relief beginning within the first few weeks and often lasting for several months. Although the pain relief usually is life-long, patients can be treated at intervals varying from as short as $8-12$ weeks to as long as 1 year, if needed [11]. The only significant toxic effect associated with ${ }^{153} \mathrm{Sm}$-EDTMP is mild transient myelosuppression $[1,8-10,12]$.

The manufacturing process of ${ }^{153} \mathrm{Sm}$-EDTMP leads to contamination with ${ }^{154} \mathrm{Eu}$ (Europium-154) which has a physical half-life of 8.5 years [2]. A previous study alluded to the retention of ${ }^{154} \mathrm{Eu}$ in the bones after receiving treatment with ${ }^{153} \mathrm{Sm}$-EDTMP [2].

\section{Method and Materials}

Two out of 15 patients who received ${ }^{153} \mathrm{Sm}$-EDTMP at Roger Maris Cancer Center activated the radiation sensors while passing through check-points; one at a US airport and the other while crossing the American-Canadian border. We assume that the ${ }^{154} \mathrm{Eu}$ which remained in the patients' bones activated the sensors. In order to investigate this hypothesis we obtained the consent from 3 of our 15 patients who received ${ }^{153} \mathrm{Sm}$-EDTMP within the previous 4 months to 2 years, including the patient who had activated the radiation alarm at the airport.

The criteria used to select those 3 patients included: they had a ${ }^{153} \mathrm{Sm}$-EDTMP dose between $75 \mathrm{mCi}$ and $107 \mathrm{mCi} 4$ months to 2 years prior to the study and live close to our facility for their own convenience. 


\begin{tabular}{|c|c|c|c|}
\hline $\begin{array}{c}\text { Case Reports in } \\
\text { Ence.ail }\end{array}$ & $\begin{array}{l}\text { Case Rep Oncol 2009;2:157-161 } \\
\text { DOI: 10.1159/000235809 }\end{array}$ & Published online: August 28, 2009 & \begin{tabular}{|l} 
@ 2009 S. Karger AG, Basel \\
ISSN 1662-6575 \\
www.karger.com/cro
\end{tabular} \\
\hline
\end{tabular}

Portable handheld meters were used to determine if an increased exposure or count rate could be measured in these patients. The sensitivity of a Geiger-Müller detector (Ludlum Measurements Inc., Sweetwater, Tex., USA) was not sufficient to detect an exposure increase beyond background levels; however, a small increase was observed when a scintillation detector (Ludlum Measurements Inc.) indicated a count rate up to twice the background level at a patient's surface.

To investigate the emission spectra emanating from these patients, a SPECT gamma camera was calibrated with the collimators removed to display a graphical readout of counts versus energy. The camera was calibrated with high energy sources between $511 \mathrm{keV}$ and $1.3 \mathrm{MeV}$ to improve its accuracy. Since the official energy range of the scanner was from $50-511 \mathrm{keV}$, additional offline correction factors obtained during the calibration procedure were used to improve the accuracy of our measurements.

Prior to each scan, the test patients were removed from the area and a background measurement was obtained. With the crystal approximately $30 \mathrm{~cm}$ from the patient's surface, the scanner was run in a cumulative mode until a predetermined count value was reached.

\section{Results}

The 5 observed peak energies were extracted during the analysis of the graphical printouts. All 3 patients exhibited identical spectral images. Fig. 1 shows the observed peaks prior to the offline corrections. Applying the offline correction factors to the peaks revealed the following energies with an uncertainty of $\pm 7.5 \mathrm{keV}: 1,277,1,003,877,729$, and $595 \mathrm{keV}$. The most probable emissions between $511 \mathrm{keV}$ and $1.3 \mathrm{MeV}$ for ${ }^{154} \mathrm{Eu}$ are $1,274.4,1,004.7,996.3,873.2,723.3$, and $591.8 \mathrm{keV}$ [13-15]. The agreement of the measured values to within $1 \%$ of the expected energies supports our theory that the increased count rates and observed spectra are the result of ${ }^{154} \mathrm{Eu}$ emissions.

An additional scan was performed on 1 patient with the scan window set to count the most probable ${ }^{154} \mathrm{Eu}$ emission, a $123 \mathrm{keV}$ gamma ray [14]. After selecting the appropriate calibration settings the counting window was centered on $123 \mathrm{keV}$ with a $15 \%$ energy window. The measured counts increased by a factor of 9 from 0.1 to $0.9 \mathrm{kcts} / \mathrm{s}$ with a visible peak at $123 \mathrm{keV}$. With this lower energy window setting we observed increased count rates on the posterior side of all patients. We have attributed this observation to the accumulation of ${ }^{154} \mathrm{Eu}$ in the vertebral bodies, which results in less attenuating tissue between the source of emissions and the detector when counting on the posterior side.

\section{Conclusion}

The low amounts of residual ${ }^{154} \mathrm{Eu}$ remaining in patients' bones after receiving ${ }^{153} \mathrm{Sm}$ EDTMP treatment cannot be reliably detected using standard handheld detectors, with the exception of scintillation detectors placed very close to the patient. Since many of ${ }^{154} \mathrm{Eu}$ 's emissions are in the high $\mathrm{keV}$ range, these types of detectors do not have the necessary efficiency to directly detect the majority of emitted photons. The increased efficiency afforded by larger stationary detectors used by local and federal authorities could easily detect an increase in counts beyond background levels over a wide spectrum of energies.

The potential activation of the sensors at checkpoints should not be a limitation to the use of ${ }^{153} \mathrm{Sm}$-EDTMP as previous studies have shown the additional radiation burden is negligible [16].

Authorized users of ${ }^{153} \mathrm{Sm}$-EDTMP should be aware of the additional implication associated with the presence of ${ }^{154} \mathrm{Eu}$. Physicians should use their discretion in informing 
patients about the residual amount of ${ }^{154} \mathrm{Eu}$ and the potential activation of the detectors at the Homeland security checkpoints.

Roger Maris Cancer Center has started providing the patients who have received ${ }^{153} \mathrm{Sm}$-EDTMP with laminated cards stating the date and the dose of treatment, as well as a statement that the holder may activate the alarm at the security checkpoint. We strongly recommend other treatment centers to also provide their patients with the laminated cards to assure the patients safety.

Fig. 1. A graphical printout of counts versus energies without offline corrections applied (obtained from a patient 2 years after injection by a gamma camera without collimators). Energies above $855 \mathrm{keV}$ are by a factor of 10 greater than indicated on the graph, as verified with calibration sources.

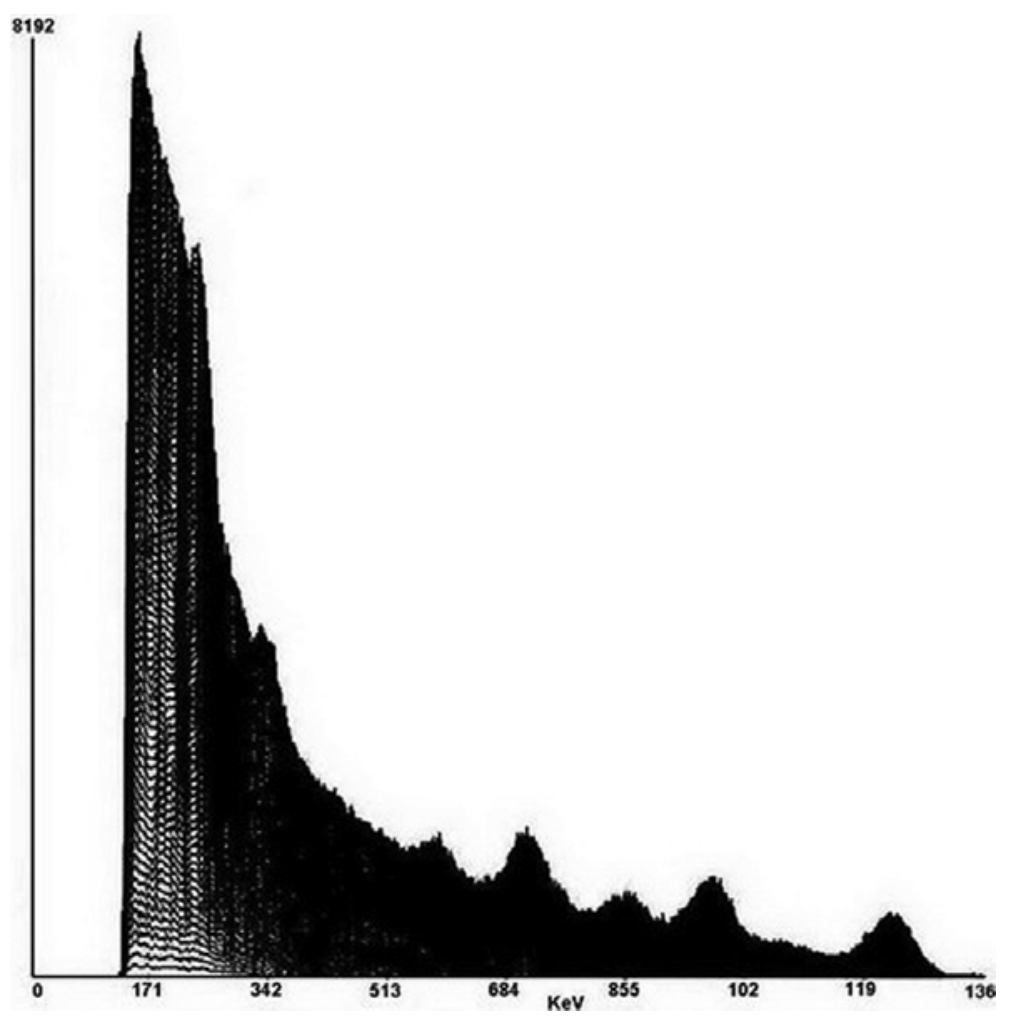




\section{References}

1 Resche I, Chatal JF, Pecking A, Ell P, Duchesne G, Rubens R, et al: A dosecontrolled study of ${ }^{153} \mathrm{Sm}$-EDTMP in the treatment of patients with painful bone metastases. Eur J Cancer 1997;33:1583-1591.

2 Moro L, Fantinato D, Frigerio F, Shamhan G, Angelovski G: Europium-154 contamination levels in Samarium-153-EDTMP for radionuclide therapy. J Phys: Conf Ser 2006;41:535-537.

-3 Sartor O, Reid RH, Hoskin PJ, Quick DP, Ell PJ, Coleman RE, Kotler JA, Freeman LM, Olivier P; Quadramet 424Sm10/11 Study Group: Samarium-153-Lexidronam complex for treatment of painful bone metastases in hormone-refractory prostate cancer. Urology 2004;63:940-945.

4 Serafini AN: Current status of systemic intravenous radiopharmaceuticals for the treatment of painful metastatic bone disease. Int J Radiat Oncol Biol Phys 1994;30:1187-1194.

5 Lewington VJ: Targeted radionuclide therapy for bone metastases. Eur J Nucl Med 1993;20:66-74.

6 Schlien B, Terpilak MS (eds): The Health Physics and Radiological Health Handbook. Olney, Md., Nucleon Lectern Associates Ins., 1984.

7 Eary JF, Collins C, Stabin M, Vernon C, Petersdorf S, Baker M, et al: Samarium ${ }^{153} \mathrm{Sm}$-EDTMP biodistribution and dosimetry estimation. J Nucl Med 1993;34:1031-1036.

-8 Collins C, Eary JF, Donaldson G, Vernon C, Bush NE, Petersdorf S, et al: Samarium ${ }^{153} \mathrm{Sm}$-EDTMP in the treatment of prostate cancer: a phase I/II trial. J Nucl Med 1993;34:1839-1844.

-9 Singh A, Holmes RA, Fraghani M, et al: Human pharmacokinetics of samarium153-EDTMP in metastatic cancer. J Nucl Med 1989;30:1814-1818.

10 Farghani M, Holmes RA, Volkert WA, et al: Samarium-153-EDTMP: pharmacokinetics, toxicity and pain response using an escalating dose schedule in treatment of metastatic bone cancer. J Nucl Med 1992;33:1451-1458.

11 Goeckeler WF, Edwards B, Volkert WA, Holmes CA, Simon J, Wilson D: Skeletal localization of samarium-153 chelates: potential therapeutic bone agents. J Nucl Med 1987;28:495-504.

12 Serafini AN, Houston SJ, Resche I, et al: Palliation of pain associated with metastatic bone cancer using samarium-153 lexidronam: a double-blind placebocontrolled clinical trial. J Clin Oncology 1998;16:1574-1581.

13 National Nuclear Data Center: ENSDF Decay Data in the MIRD Format. [Database Version 4 March 2009 online]. http://www.nndc.bnl.gov/mird. Accessed March 16, 2009.

14 X-Ray and Gamma-ray standards for detector calibration. IAEA-TECDOC-619 Evaluated Data 1991, p 154.

15 Juliano J, Stephens F: Decay of Europium-154. Phys Rev 1957;108:341-348.

16 Ramamoorthy N, Saraswathy P, Das MK, Mehra K, Ananthakrishnan M: Production logistics and radionuclidic purity aspects of ${ }^{153} \mathrm{Sm}$ for radionuclide therapy. Nucl Med Commun 2002;23:83-89. 